\title{
Researches on the freezing of blueberries and green bean pods using an experimental model of a fast freezing equipment
}

\author{
Cristian Sorica ${ }^{1, *}$, Marian Vintilă ${ }^{2}$, Ion Pirnă ${ }^{3}$, Ion Grigore ${ }^{1}$, Mario Cristea ${ }^{1}$, \\ Laurențiu Vladuțoiu ${ }^{1}$, Elena Sorica ${ }^{1}$, Irina Neacșu Bălănescu ${ }^{4,5}$, Cristina Grosu ${ }^{6}$, \\ Marius Raischi $^{7}$ and Marga Grădilă ${ }^{4}$ \\ ${ }^{1}$ INMA Bucharest, Romania \\ ${ }^{2}$ ICDIMPH-Horting Bucharest, Romania \\ ${ }^{3}$ ASAS, Romania \\ ${ }^{4}$ ICDPP Bucharest, Romania \\ ${ }^{5}$ USAMV Bucharest, Romania \\ ${ }^{6}$ INCDTP Bucharest, Romania \\ ${ }^{7}$ INCDPM Bucharest, Romania
}

\begin{abstract}
In order to conserve perishable food and extend the permissible storage and marketing period, one of the best methods that uses artificial frost is freezing. The action of low temperatures leads to a slowing down of the modifying processes, both nutritionally and organoleptically. The researches presented within the paper aims to determine some specific parameters for the freezing process using an experimental model of a fast freezing equipment with liquid nitrogen. Experimental researches use two species of horticultural products, namely blueberries and green bean pods. The results indicate that the values of total freezing time, average linear freezing rate and liquid nitrogen consumption for quick freezing of blueberries were higher than those recorded for green bean pods. Also, with the lowering of the set temperature inside the freezing chamber, the freezing time from $0{ }^{\circ} \mathrm{C}$ to the temperature of $-15{ }^{\circ} \mathrm{C}$ decreases, resulting in lower freezing times, higher average linear freezing rates and liquid nitrogen consumptions with increasing tendency.
\end{abstract}

\section{Introduction}

In order to extend the permissible period of storage and marketing of perishable foodstuffs, a number of conservation methods and techniques can be applied [1-6]: preservation by using low temperatures (refrigeration, freezing, modified atmosphere); preservation by using high temperatures (pasteurization, sterilization); conservation by reducing the water content of the product (dehydration, concentration); preservation by the use of inhibitors of

\footnotetext{
"Cristian Sorica: cri_sor2002@yahoo.com
} 
depreciation phenomena (natural antimicrobials, bacteriocins, sugar addition, acidification, chemical preservatives etc.); preservation by unconventional methods (ionizing radiation, high pressure, high voltage electrical impulses, non-ionizing radiation, ozone, ultrasound, photodynamics, etc.). Of all these processes, the use of artificial cold (refrigeration, freezing) leads to the best results when it is desired to keep the attributes and quality as close as possible to those of the fresh product [7-9].

For long-term storage, in order to use the products in the off-season, freezing is frequently used. By freezing the admissible storage time of the products is increased by over 5 ... 50 times the preservation by refrigeration [10].

Generally, freezing occurs at temperatures between $-18{ }^{\circ} \mathrm{C}$ and $-40{ }^{\circ} \mathrm{C}$. Depending on the temperature at which it occurs, freezing can be:

- slow, carried out at temperatures of $-18{ }^{\circ} \mathrm{C} \ldots 20^{\circ} \mathrm{C}$ for about 80 hours;

- semi-rapid, at temperatures between $-20{ }^{\circ} \mathrm{C}$ and $40{ }^{\circ} \mathrm{C}$ (in cold rooms or freezing tunnels) and lasting about 60 hours;

- fast, conducted at temperatures of $-30{ }^{\circ} \mathrm{C}$ to $-35^{\circ} \mathrm{C}$ and lasting up to 24 hours;

- ultrafast, carried out at $-35^{\circ} \mathrm{C}$ to $-40{ }^{\circ} \mathrm{C}$ and lasting about 3 hours.

The freezing rate determines the formation of ice crystals as follows: slow freezing ("classic") leads to the formation of a small number of ice crystals having large dimensions, while rapid freezing with cryogenic liquids generates a large number of small size crystals. Large crystals resulting from slow freezing cause deformation, dislocation, and perforation of cell walls, and when defrosting these products, juice losses are high. In the case of rapid freezing with cryogenic fluids, tissue changes due to the formation of ice crystals are less damaging, and defrosting juice losses are lower because much of the water remains in the cells $[11,12]$.

The quality of frozen fruits and vegetables depends to a certain extent on the characteristics of the raw material used. Compatibility with freezing is a function of the species, climate and soil characteristics when the fruit and vegetables were harvested, crop technologies (fertilization, irrigation etc.). Some species such as lettuce, tomatoes, radishes, table grapes are not suitable for freezing, because during the freezing process there are important losses of turgidity, discoloration and loss of flavor. The conditions that vegetables and fruits have to fulfill to be preserved by freezing are determined by: compatibility with freezing preservation, widespread acceptance by consumers, high technological yields, virus resistance, mold, physiological defects and insects, uniformity of maturation, good handling resistance, pronounced color and flavor, firm texture with as little as possible deformation and softening tendency to thaw, as little juice as possible in defrosting. One of the modern freezing techniques is that of cryogenic freezing using liquid nitrogen $\left(\mathrm{N}_{2}\right)$ as a cooling substance $[11,13,14]$. Compared to conventional freezing techniques, the cryogenic method has the following advantages: rapid freezing, inhibition of bacterial growth, limited dehydration, considerable reduction of quantitative losses, optimal nutritional preservation, maintenance of the appearance and taste of the food.

Among the fruit species with the widest use for freezing can be remembered berries, strawberries, cherries, peaches and apricots, and among vegetables: green peas, green beans, spinach and carrots.

\section{Materials and methods}

Two species of horticultural products, namely blueberries and green bean pods, were used in the experimental research. (Fig. 1). 

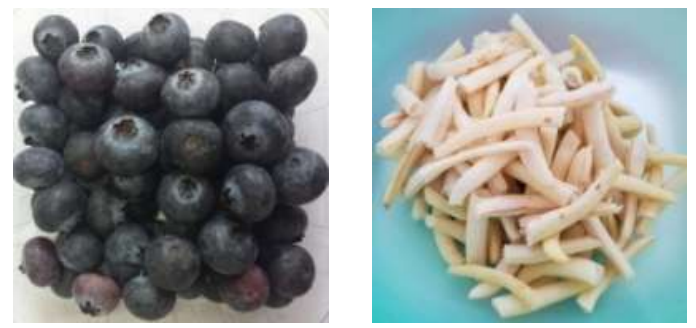

Fig. 1. Species of horticultural products used in the experimental research

For horticultural products fast freezing it has been used an experimental model of fast freezing equipment with liquid nitrogen, ECR-0, intended for cryogenic freezing of different food products (Fig. 2).

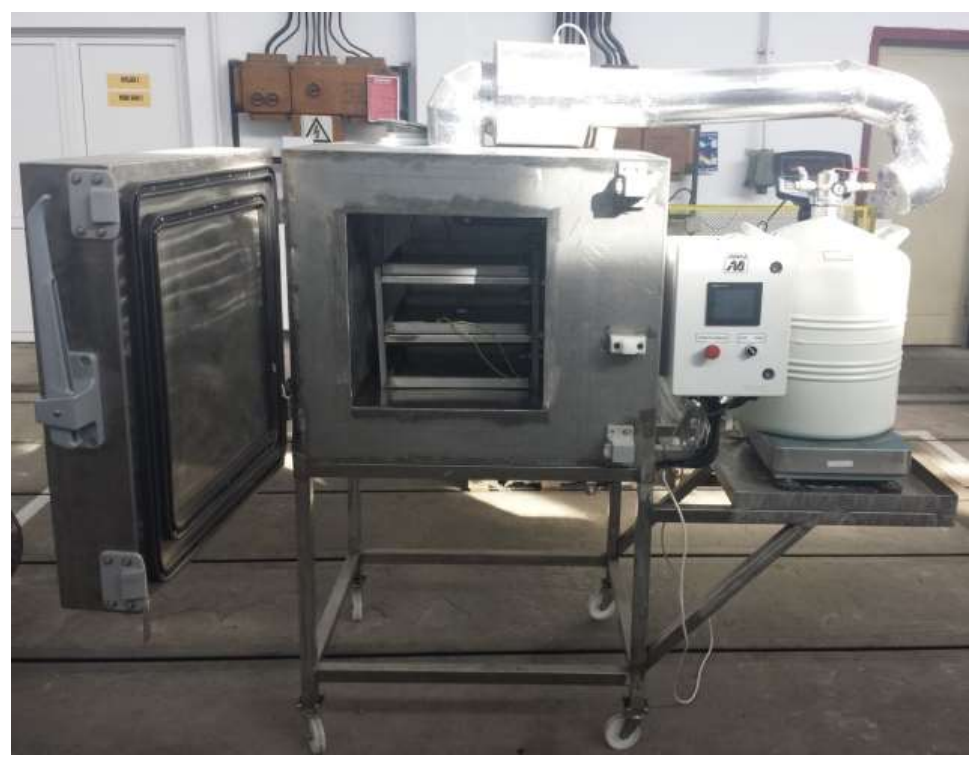

Fig. 2. Fast freezing equipment - ECR [15]

The equipment is provided with temperature sensors that allow monitoring and permanent control of process parameters, namely:

- Type K Thermocouple (chromel-alumel), probe diameter $\varphi 1.5 \mathrm{~mm}$, measuring range $-100{ }^{\circ} \mathrm{C} \ldots+30{ }^{\circ} \mathrm{C}$, allows temperature measurement in the centre of the product;

- Type $\mathrm{K}$ Thermocouple, with temperature transfer element, measuring range -100 ${ }^{\circ} \mathrm{C} \ldots+30{ }^{\circ} \mathrm{C}$, allows temperature measurement on the external surface of the product;

- Thermal resistance, type TTR Pt 100 , measuring range $-200{ }^{\circ} \mathrm{C} \ldots+30{ }^{\circ} \mathrm{C}$, allows temperature measurement inside the freezing chamber.

The chamber is provided with an access door, thermal insulated and provided with two sealing gaskets and de-icing resistances to prevent ice formation and to facilitate access to the chamber at the end of the freezing cycle. The locking system is provided with two clamps and a handle to obtain a uniform and firm closing. In order to achieve a forced convection of the atmosphere in the chamber in order to improve the thermal transfer from the product to the thermal agent, a fan was provided inside the chamber. The equipment allows operation in two working modes, namely: 
- automatic operation mode, with setting the chamber temperature limit at which ventilation starts and liquid nitrogen purging stops;

- manual operation with continuous liquid nitrogen purging.

All measured parameters during the working cycle were recorded on the SD memory card of the Programmable Logic Controller (PLC) within the automation installation of the equipment.

The weight of each sample was set at $750 \mathrm{~g}, 250 \mathrm{~g}$ on each of the 3 trays. For each sample, the mass and dimensional characteristics were determined as follows:

- for blueberries: the average bean mass, average height and the maximum equatorial diameter were determined as the average of five random measurements from the product;

- for green bean: the pods were fragmented up to lengths between 35 and $65 \mathrm{~mm}$. For these, the average mass, average length, average width and average thickness of the pods fragments were measured as the average of five random measurements from the product.

For products with regular geometric shapes, the thermal center (TC) coincides with their geometric center. The smallest distance between the TC thermal center and the outer surface of the product is noted with $\delta_{0}$ and is an important parameter for determining the freezing rate (Fig. 3). For blueberries, $\delta_{0}$ was approximated by $h / 2$ and for green bean pods with $g / 2$.

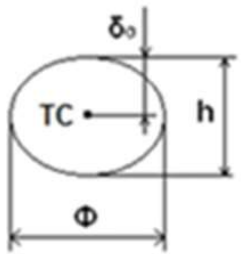

a)

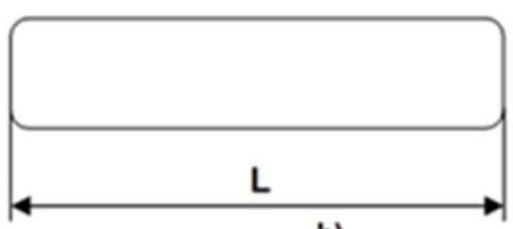

b)

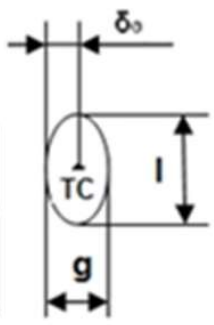

Fig. 3. Dimensional characteristics: a) - blueberries; b) - green bean pods

The freezing process is considered complete when the temperature in the product thermal centre reaches $-15^{\circ} \mathrm{C}$.

The parameters followed during the freezing process were as follows:

- Mass of the liquid nitrogen container used for freezing;

- Freezing time from $0{ }^{\circ} \mathrm{C}$ to $-15^{\circ} \mathrm{C}$;

- Total freezing time.

Following the processing of experimental data, the following energy indexes were determined:

- Average linear freezing rate;

- Liquid nitrogen consumption for a freezing cycle.

To characterize a freezing process in terms of cooling intensity, it is considered as criterion, the average linear freezing rate given by the relation:

$$
w_{m}=\frac{\delta_{0}}{\tau_{0}},[\mathrm{~cm} / \mathrm{h}]
$$

where: $\delta_{0}$ is the smallest distance between the thermal centre and the outer surface of the product, $[\mathrm{cm}]$;

$\tau_{\mathbf{0}}$ - the freezing time from a uniform initial temperature of $0^{\circ} \mathrm{C}$ to the temperature to be achieved in the thermal centre, $[h]$. 
Depending on the average freezing rate, $w_{m}$, the International Institute of Refrigeration recommends the following classification of freezing methods [16]:

- slow freezing

$$
\begin{aligned}
& w_{m}<0.5 \mathrm{~cm} / \mathrm{h} ; \\
& w_{m}=0.5 \ldots 3 \mathrm{~cm} / \mathrm{h} ; \\
& w_{m}=3 \ldots 10 \mathrm{~cm} / \mathrm{h} ; \\
& w_{m}=10 \ldots 100 \mathrm{~cm} / \mathrm{h} .
\end{aligned}
$$

- fast freezing

- very fast freezing

- ultrafast freezing

Liquid nitrogen consumption for a freezing cycle was determined by the difference between the mass of the liquid nitrogen container before and after the freezing process was completed.

\section{Results and discussion}

Following the processing and interpretation of the experimental data, the following results were obtained regarding the characterization of the two species of horticultural products used:

Table 1. Characteristics of the analysed products

\begin{tabular}{|c|l|c|c|c|}
\hline \multirow{2}{*}{ No. } & \multicolumn{1}{|c|}{ Characteristic } & \multirow{2}{*}{$\mathbf{U M}$} & \multicolumn{2}{c|}{$\begin{array}{c}\text { Value of parameters } \\
\text { determined in the tests }\end{array}$} \\
\cline { 4 - 5 } & & & Blueberries & $\begin{array}{c}\text { Green bean } \\
\text { pods }\end{array}$ \\
\hline 1. & Sample mass & $g$ & $250 \times 3=750$ & $200 \times 3=600$ \\
\hline 2. & Average mass of a product & $m m$ & 1.72 & 1.29 \\
\hline 3. & $\begin{array}{l}\text { Maximum equatorial diameter (for } \\
\text { blueberries), } \Phi\end{array}$ & $m m$ & 12.07 & - \\
\hline 4. & Bean average height (for blueberries), $h$ & - & 48.77 \\
\hline 5. & $\begin{array}{l}\text { Average length of the pod fragment (for green } \\
\text { bean pods), } L\end{array}$ & $m m$ & - & 8.79 \\
\hline 6. & $\begin{array}{l}\text { Average width of the pod fragment (for green } \\
\text { bean pods), } l\end{array}$ & $m m$ & - & 6.75 \\
\hline 7. & $\begin{array}{l}\text { Average thickness of the pod fragments (for } \\
\text { green bean pods), } g\end{array}$ & $m m$ & - & 3.38 \\
\hline 8. & $\begin{array}{l}\text { The smallest distance between the thermal } \\
\text { centre and the outer surface of the product, } \delta_{0}\end{array}$ & $m m$ & 6.04 & - \\
\hline
\end{tabular}

Process parameters, during the freezing process, can be determined by direct reading on the touch screen of the command and control panel or by post-processing the data recorded on the SD memory card. Freezing times were determined based on the data recorded on the SD memory card (Fig. 4), as follows:

- the freezing time from $0^{\circ} \mathrm{C}$ to $-15^{\circ} \mathrm{C}$ was determined by the difference between the total timer recorded at the end of the freezing process $\left(-15^{\circ} \mathrm{C}\right)$ and timer recorded when the temperature reached $0^{\circ} \mathrm{C}$ in the product's thermal centre;

- the total freezing time was determined by direct reading of the total timer recorded at the end of the freezing process. 


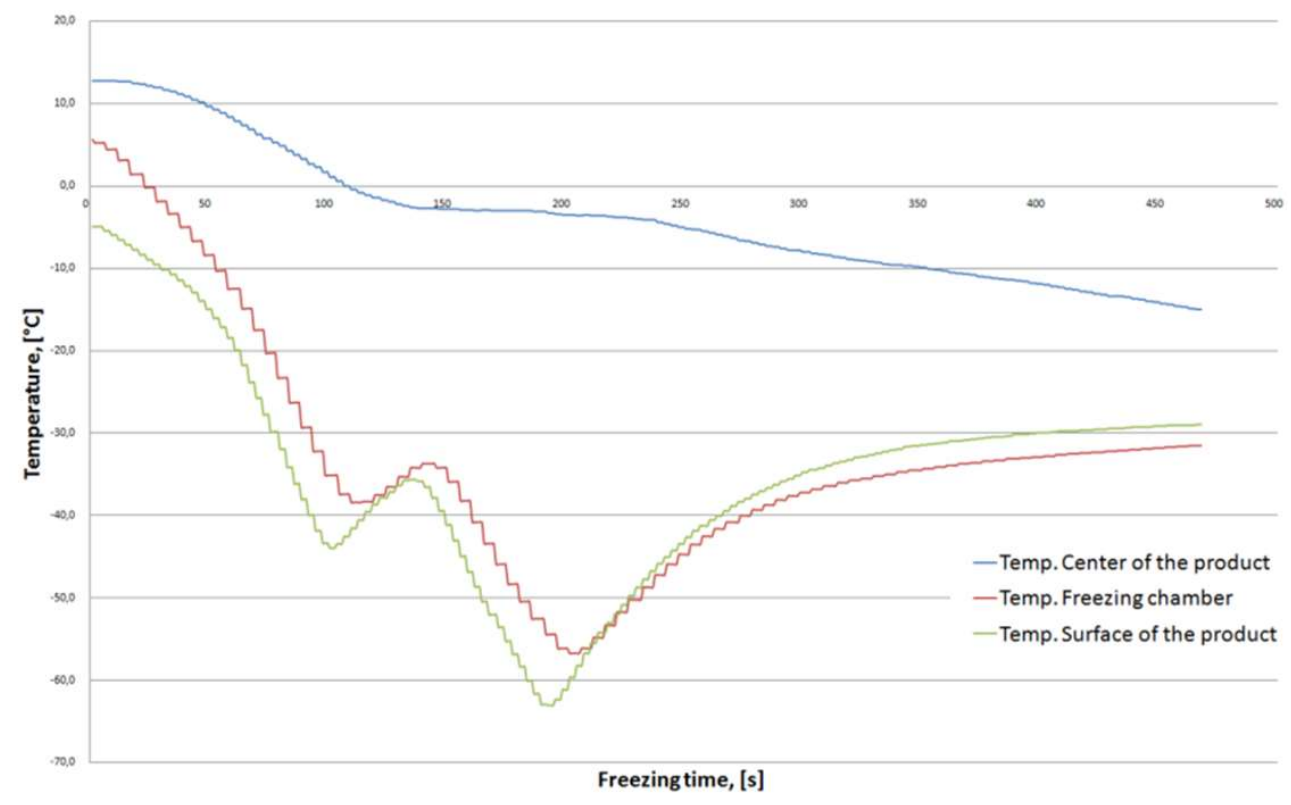

Fig. 4. Determination of the process temperatures based on data recorded by sensors

The parameters followed during the freezing process and the energetic indexes of fast freezing equipment are shown in Table 2.

Table 2. The parameters followed during the freezing process

\begin{tabular}{|c|c|c|c|c|c|c|c|c|}
\hline \multirow[t]{2}{*}{ No. } & \multirow{2}{*}{ Characteristic } & \multirow[t]{2}{*}{ U.M } & \multicolumn{6}{|c|}{$\begin{array}{c}\begin{array}{c}\text { Value of parameters determined in the } \\
\text { tests }\end{array} \\
\end{array}$} \\
\hline & & & \multicolumn{3}{|c|}{ Blueberries } & \multicolumn{3}{|c|}{ Green bean pods } \\
\hline & & & \multicolumn{6}{|c|}{ The chamber temperature limit set to $\left[{ }^{\circ} \mathrm{C}\right]$} \\
\hline & & & -30 & -35 & -40 & -30 & -35 & -40 \\
\hline 1. & Freezing time from $0^{\circ} \mathrm{C}$ to $-15^{\circ} \mathrm{C}$ & $s$ & 355 & 250 & 234 & 383 & 239 & 187 \\
\hline 2. & Total freezing time & $S$ & 467 & 364 & 343 & 433 & 303 & 255 \\
\hline 3. & $\begin{array}{l}\text { Average linear freezing rate for an } \\
\text { operating cycle }\end{array}$ & $\mathrm{cm} / \mathrm{h}$ & 6.13 & 8.70 & 9.29 & 3.18 & 5.09 & 6.51 \\
\hline 4. & $\begin{array}{l}\text { Liquid nitrogen consumption for an } \\
\text { operating cycle }\end{array}$ & $k g$ & 2.30 & 3.06 & 2.16 & 0.90 & 1.60 & 2.50 \\
\hline
\end{tabular}

Graphical reprezentation of the results is shown in Fig. 5. 


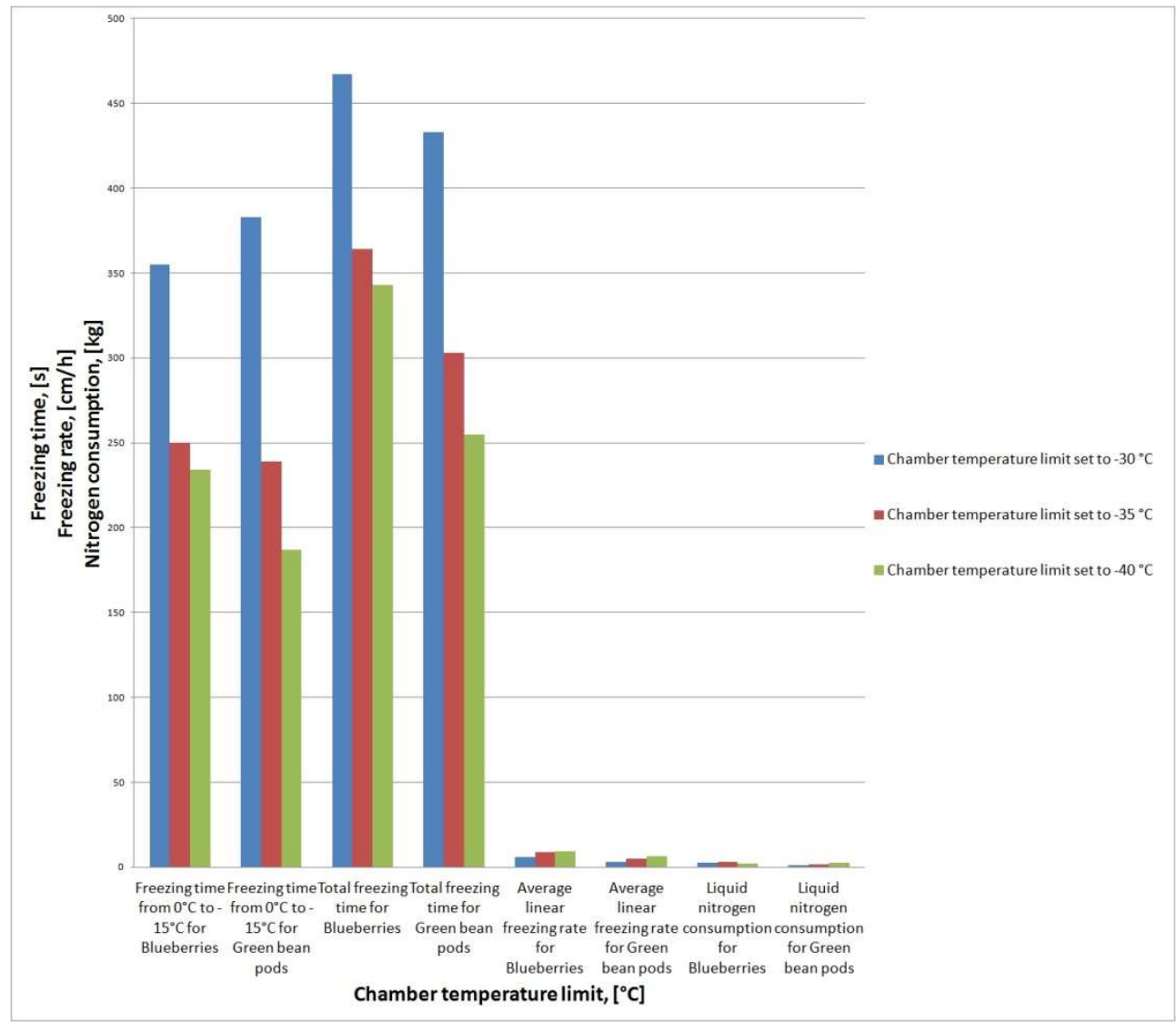

Fig. 5. Graphical reprezentation of the results

The total freezing times and the average linear freezing rates depending on the selected temperature limits within the chamber, are presented, both for blueberries and green bean pods, in Fig. 6 and 7.
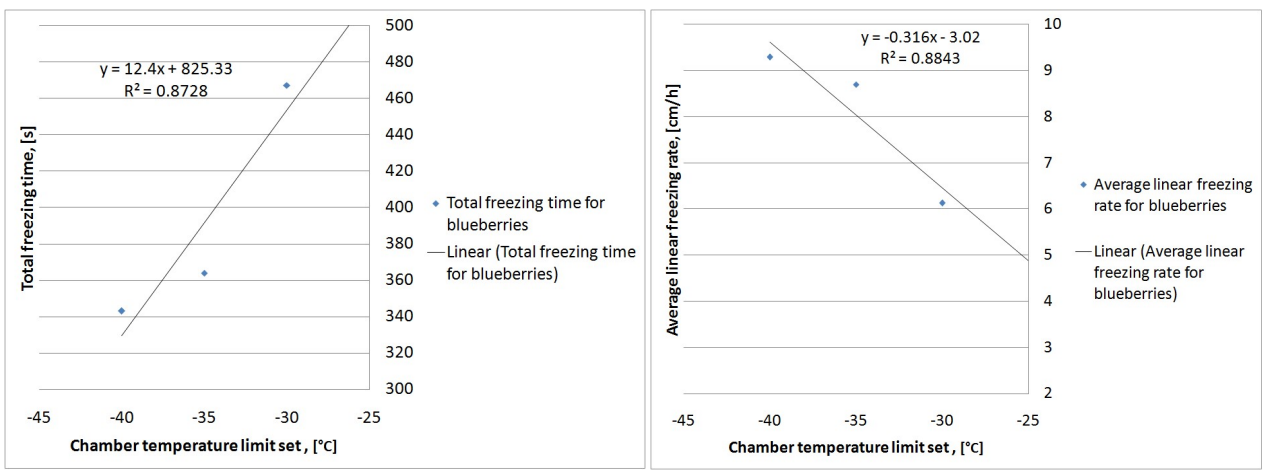

Fig. 6. The total freezing times and the average linear freezing rates depending on the selected temperature limits within the chamber, for blueberries 

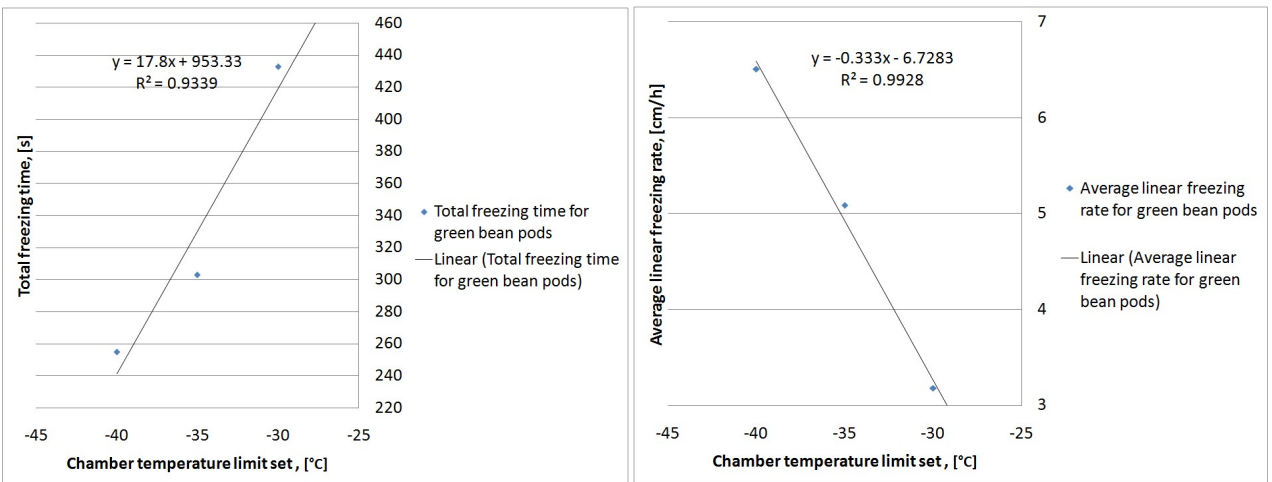

Fig. 7. The total freezing times and the average linear freezing rates depending on the selected temperature limits within the chamber, for green bean pods

Linear regressions performed using Excel, allowed the identification of some linear functions, which estimate the variation of the total freezing time and the average linear freezing rate depending on the selected temperature limit within the chamber, with coefficients of determination varying from 0.87 to 0.99 .

Samples aspect before and after freezing is shown in Table 3:

Table 3. Samples aspect during the experimentation

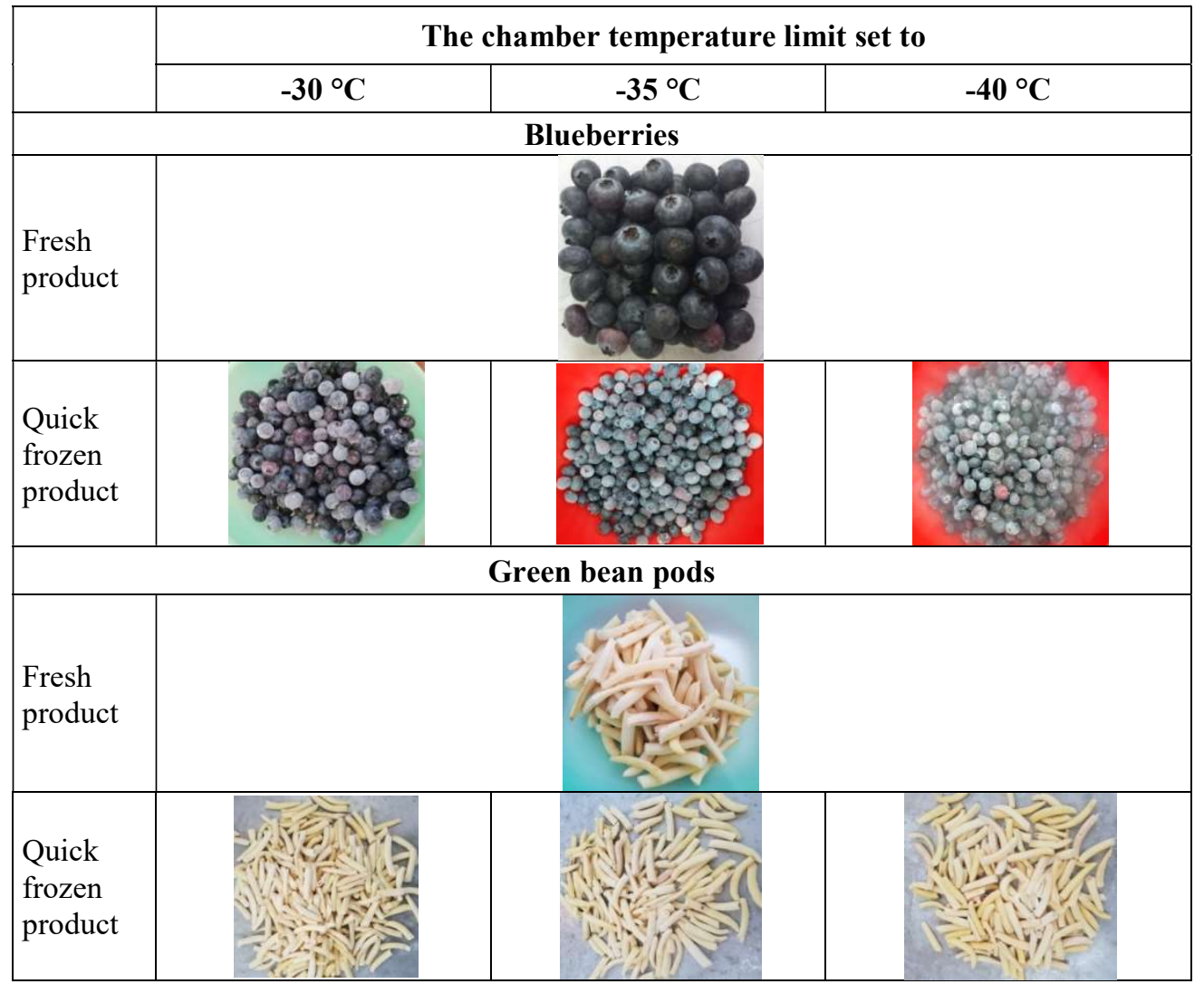




\section{Conclusions}

Following the determinations made during the experimentation and data processing, the following results were obtained:

- with the lowering of the set temperature inside the freezing chamber, the freezing time from $0{ }^{\circ} \mathrm{C}$ to the temperature of $-15^{\circ} \mathrm{C}$ decreases, resulting in lower freezing times;

- with the lowering of the set temperature inside the freezing chamber, higher average linear freezing rates are obtained;

- with the lowering of the set temperature inside the freezing chamber, the liquid nitrogen consumptions record an increasing tendency;

- the total freezing time for blueberries was higher than the freezing time for green bean pods, regardless of the set temperature inside the freezing chamber;

- the average linear freezing rate for blueberries was higher than the freezing rate for green bean pods, regardless of the set temperature inside the freezing chamber;

- the liquid nitrogen consumption for freezing blueberries was, overall, higher than the nitrogen consumption for green bean pods.

\section{Acknowledgement}

This work was supported by a grant of the Romanian Research and Innovation Ministry, through Programme 1 - Development of the national research-development system, subprogramme 1.2 - Institutional performance - Projects for financing excellence in RDI, contract no. 16PFE.

\section{References}

1. A. Alhamdan, B. Hassan, H. Alkahtani, D. Abdelkarim, M. Younis, Cryogenic freezing of fresh date fruits for quality preservation during frozen storage, Journal of the Saudi Society of Agricultural Sciences, Volume 17, Issue 1, Pages 9-16, (2018);

2. A. Alhamdan, B. Hassan, H. Alkahtani, D. Abdelkarim, M. Younis, Freezing of fresh Barhi dates for quality preservation during frozen storage, Saudi Journal of Biological Sciences, Volume 25, Issue 8, Pages 1552-1561, (2018);

3. A. Bigliaa, L. Combaa, E. Fabriziob, P. Gaya, D. R. Aimoninoa, Case studies in food freezing at very low temperature, Energy Procedia 101, Pages 305-312, (2016);

4. C. Bilbao-Sainz, A. Sinrod, M. J. Powell-Palm, L. Dao, G. Takeoka, T. Williams, D. Wood, G. Ukpai, J. Aruda, D. F. Bridges, V. C.H. Wu, B. Rubinsky, T. McHugh, Preservation of sweet cherry by isochoric (constant volume) freezing, Innovative Food Science \& Emerging Technologies, Volume 52, Pages 108-115, (2019);

5. M. J.Sousa-Gallagher, A. Tank, R. Sousa, The Stability and Shelf Life of Food (Second Edition), Woodhead Publishing Series in Food Science, Technology and Nutrition, Pages 399-430, (2016);

6. M. Ingeaua, T. Prisecaru, I. Pirna, C. Sorică, Analysis of a convective drying process of plums, INMATEH Agricultural Engineering, Volume 46, no. 2 / 2015, e-ISSN 2068-2239, p-ISSN 2068-4215, Pages 115 - 124;

7. M. S. Aghdam, S. Bodbodak, Food Bioprocess Technology, Volume 7, Issue 1, Pages 37- 53, Springer US, p-ISSN 1935-5130, e-ISSN 1935-5149, (2014);

8. X. Cao, F. Zhang, D. Zhao, D. Zhu, J. Li, Effects of freezing conditions on quality changes in blueberries, Journal of the Science of Food and Agriculture, Volume 98, Issue 12, ISSN $0022-$ 5142, e-ISSN 1097-0010, Pages 4673-4679, (2018);

9. P. K. Jha, E. Xanthakis, S. Chevallier, V. Jury, A. Le-Bail, Assessment of freeze damage in fruits and vegetables, Food Research International, Available online, (2018); 
10. P. Niculita, Refrigeration technique and technology in agri-food fields, Didactic and Pedagogical Publishing House R.A, Bucharest, ISBN 973-30-5719-3, (1998);

11. P. J. Fellows, Food Processing Technology (Fourth Edition): Principles and Practice, Woodhead Publishing Series in Food Science, Technology and Nutrition, Pages 885-928, (2017);

12. C. Kennedy, Food Preservation Techniques, Woodhead Publishing Series in Food Science, Technology and Nutrition, Pages 228-240, (2003);

13. V. Damian, C. Iosifescu, G. Coman, Environmentally friendly method for freezing raspberries and blueberries using liquid nitrogen, Environmental Engineering and Management Journal, Volume 9, Issue 10, ISSN 1582-9596, Pages 1319-1322, (2010);

14. V. Damian, C. Iosifescu, G. Coman, M. Dragan, E. O. Constantin, Theoretical and experimental study on cryogenic freezing of berries, Advances in Communications, Computers, Systems, Circuits and Devices, European Conference of Systems-Proceedings, ISBN 978-960-474-250-9, ISSN 1792-6637, Pages 171-174, (2010);

15. Sectoral Research Program of the Ministry of Agriculture and Rural Development, ADER 16.2.1: Researches on thermal, physical properties, heat and mass transfer coefficients of horticultural products for the optimization of freezing technologies applied on cold chains, 2015 - 2018;

16. L. Bøgh-Sørensen, Recommendations for the processing and handling of frozen foods, IIR, (2006). 